\title{
What triggers requests for ethics consultations?
}

Gordon DuVal, Leah Sartorius, Brian Clarridge, Gary Gensler and Marion Danis University of Toronto, National Institutes of Health, Bethesda, Maryland, University of Massachusetts, Boston, EMMES Corporation, Potomac, Maryland and National Institutes of Health, respectively

\begin{abstract}
Objectives-While clinical practice is complicated by many ethical dilemmas, clinicians do not often request ethics consultations. We therefore investigated what triggers clinicians' requests for ethics consultation. Design-Cross-sectional telephone survey. Setting-Internal medicine practices throughout the United States.

Participants-Randomly selected physicians practising in internal medicine, oncology and critical care.

Main measurements-Socio-demographic characteristics, training in medicine and ethics, and practice characteristics; types of ethical problems that prompt requests for consultation, and factors triggering consultation requests.

Results-One hundred and ninety of 344 responding physicians (55\%) reported requesting ethics consultations. Physicians most commonly reported requesting ethics consultations for ethical dilemmas related to end-of-life decision making, patient autonomy issues, and conflict. The most common triggers that led to consultation requests were: 1 ) wanting help resolving a conflict; 2) wanting assistance interacting with a difficult family, patient, or surrogate; 3) wanting help making a decision or planning care, and 4) emotional triggers. Physicians who were ethnically in the minority, practised in communities under 500,000 population, or who were trained in the US were more likely to request consultations prompted by conflict.

Conclusions-Conflicts and other emotionally charged concerns trigger consultation requests more commonly than other cognitively based concerns. Ethicists need to be prepared to mediate conflicts and handle sometimes difficult emotional situations when consulting. The data suggest that ethics consultants might serve clinicians well by consulting on a more proactive basis to avoid conflicts and by educating clinicians to develop mediation skills.

(Fournal of Medical Ethics 2001;27 supp1 I:i24-i29)
\end{abstract}

Keywords: Ethics consultation; resolution of ethical problems; ethical conflicts

\section{Introduction}

Increasingly, health care facilities are establishing ethics consultation services composed of experts who apply ethical reasoning to dilemmas encountered in medical practice. ${ }^{1}$ Yet, in spite of the breadth and complexity of ethical dilemmas in medicine, clinicians have been slow to use these specialised services.

One possible reason for this is that an ethical quandary as such does not prompt requests for a consultation. We hypothesise that consultation requests are usually triggered by concrete factors, such as the need to handle a difficult situation or resolve a conflict, rather than by a desire to use or apply ethical reasoning. An awareness of the factors that are associated with requests for consultations will enable consultants more effectively to address the ethical problems faced by clinicians, and will facilitate the integration of consultation services into the clinical setting.

We report a sub-analysis of a survey of internists in the United States in order to determine the factors that trigger requests for ethics consultations.

\section{Methods}

STUDY POPULATION

A national sample of 600 internists was randomly selected from the American Medical Association Master List of Physicians and Medical Students for Mailing Purposes. We randomly sampled 200 cases from each of: critical care and pulmonary critical care medicine $(n=2,334)$; medical oncology and haematology/oncology $(n=6,536)$; and internists, not otherwise specified $(n=95,885)$. This selection strategy captured both physicians who serve patients with life-threatening illnesses and physicians serving more general patient populations. Following randomisation, physicians were deemed ineligible for this study only if they reported that they had not been in practice for a year or if they spent less than $20 \%$ of their time in direct patient care. Those physicians who acknowledged ever requesting an ethics consultation comprise the sample reported here. Results regarding those physicians who did not request a consultation will be reported elsewhere.

\section{QUESTIONNAIRE}

Telephone interviews were conducted between October 1999 and March 2000 by trained interviewers from the Center for Survey Research at the University of Massachusetts, Boston. The interviews took an average of 26 minutes to complete and included both closed and open-ended items. 
The questionnaire used during the telephone interviews was composed of four sections: 1) questions regarding the types of ethical dilemmas faced at the physician's predominant practice site; 2 ) the strategies and resources used to address ethical dilemmas; 3) the need for, use of, and satisfaction with ethics consultation services, and 4) items regarding demographic data, education, practice characteristics and experience with medical ethics (the questionnaire is available upon request).

Participation was voluntary. The study was reviewed and exempted from institutional review board review by the Office of Human Subject Research at the National Institutes of Health.

\section{ANALYSIS}

From the broader survey, the following open-ended questions were analysed for the purposes of this report:

1. What was the situation that led to the most recent request [for an ethics consultation in which you participated]?

2. Was there something specific that triggered the request for an ethics consultation? If yes, please specify.

Verbatim responses were analysed using a coding scheme that was developed by a consensus process. Investigators reviewed a $20 \%$ random sample of responses to identify major themes and to establish coding schemes for each of the two questions. The coding scheme developed for question 1 included general categories of ethical dilemmas and issues (table 1). The coding scheme developed for question 2 identified triggers that lead physicians to request a consult (table 2 ). Two investigators (GD and LS) separately coded the responses. Because the description of the trigger sometimes involved multiple elements, two codes were assigned to some responses. Three investigators (GD, LS, and MD) discussed coding disagreements until consensus was achieved. The coded data was then reviewed

Table 1 Recent ethical dilemmas that have led to ethics consultation requests

\begin{tabular}{lrr}
\hline Dilemma & \multirow{2}{*}{$N$} & $\%$ \\
\hline $\begin{array}{l}\text { End-of-life issues (futility, withdrawal of life-sustaining } \\
\quad \text { treatment, etc) }\end{array}$ & 154 & 74.0 \\
Patient autonomy (decisions made on behalf of patient) & 119 & 57.2 \\
Conflict (between or among involved persons) & 82 & 39.4 \\
$\begin{array}{l}\text { Other (includes genetics, abortion, substance abuse) } \\
\text { Religious and cultural issues }\end{array}$ & 13 & 6.3 \\
$\begin{array}{l}\text { Professional conduct (questions about possible } \\
\text { misconduct) }\end{array}$ & 11 & 5.3 \\
$\begin{array}{l}\text { Truth-telling and confidentiality } \\
\text { Justice issues (insurance, managed care and fair access }\end{array}$ & 9 & 4.3 \\
$\quad$ to health care & 2 & 1.0 \\
$\begin{array}{l}\text { Beneficence (the best way to promote the patient's } \\
\quad \text { welfare) }\end{array}$ & 2 & 1.0 \\
\hline
\end{tabular}

Note: Results add up to more than $100 \%$ because up to three category codes were applied to responses. Responses of "don't know," "no," (which comprised $5 \%$ ) and uninterpretable responses $(0.5 \%)$ were omitted from the table.
Table 2 Factors that trigger ethics consultation requests

\begin{tabular}{lrr}
\hline Trigger & \multirow{2}{*}{$N$} & $\%$ \\
\hline Category 1 & 66 & 34.6 \\
Wants help resolving a conflict & 19 & 10.0 \\
Wants help interacting with a difficult patient or family & 17 & 8.9 \\
Has emotional trigger & & \\
Category 2 & 25 & 13.1 \\
Wants help in making a decision or planning care & 15 & 7.9 \\
Has regulatory/legal/administrative reasons & 12 & 6.3 \\
Repeats previously described ethical problem & 8 & 4.2 \\
Wants help thinking through ethical issues & 7 & 3.7 \\
Someone else requested the ethics consultation & 6 & 3.1 \\
Wants assistance with communication & & \\
Has concern about the fairness of a decision process or & 4 & 2.1 \\
$\quad$ procedural issue & 2 & 1.1 \\
Anticipates a bad situation & &
\end{tabular}

Note: Results add up to more than $100 \%$ because 2 category codes were applied to some responses. Responses of "don't remember," (which comprised $4.7 \%$ ), uninterpretable responses $(02.6 \%$ ), and other explanations $(2.6 \%)$ were omitted from the table.

for completeness and consistency within the final categories.

After assigning codes to the open-ended responses, we analysed the data using simple descriptive statistics, calculating the frequency with which each response code appeared for each question.

The triggers listed in table 2 were sorted into two categories. Category 1 responses included those in which conflict or distress on the part of some party motivated the consultation request. It includes the triggers that were labelled 1) wanting help resolving a conflict, 2) wanting help interacting with a difficult patient or family, and 3) an emotional trigger. Category 2 triggers included the remaining codes that were considered to involve processoriented, more cognitively based, or introspective reasons for requesting a consultation. Univariate and multivariate logistic regression were performed to determine which factors predict whether an ethics consultation was triggered by conflict or distress (category 1) or by more introspective reasons (category 2). Only one responding physician gave a response that involved codes in both categories. This record was excluded from the analysis. Responses indicating that a consultation was prompted by someone other than the physician, responses indicating the physician could not recall the situation, and uninterpretable responses were excluded from analysis. A total of 177 physician responses were analysed, $93 \%$ of the total.

\section{Results}

RESPONDENT CHARACTERISTICS

Of the 600 physicians selected from the AMA files, 537 met eligibility criteria. Of those, $344(64 \%)$ completed an interview, while $76(14 \%)$ actively refused. That left $117(22 \%)$ who neither completed an interview nor actively refused by the end of the field period. Roughly half of the 117 in this latter group had been contacted on several occasions to provide opportunities for participation and the other half could not be located. The distribution among the physicians completing the survey 
Table 3 Physician characteristics

\begin{tabular}{|c|c|c|}
\hline & \multicolumn{2}{|c|}{$\begin{array}{l}\text { Sampled } \\
\text { Physicians }\end{array}$} \\
\hline & $N$ & $\%$ \\
\hline \multicolumn{3}{|l|}{ Gender } \\
\hline Male & 150 & 78.9 \\
\hline Female & 40 & 21.0 \\
\hline \multicolumn{3}{|l|}{ Religion } \\
\hline Protestant & 60 & 32.2 \\
\hline Catholic including Greek Orthodox & 54 & 29.0 \\
\hline Jewish & 27 & 14.5 \\
\hline Muslim & 6 & 3.2 \\
\hline Hindu & 10 & 5.3 \\
\hline Buddhist & 2 & 1.0 \\
\hline No Religious affiliation, Atheist, Agnostic & 25 & 13.4 \\
\hline Other & 2 & 1.0 \\
\hline \multicolumn{3}{|l|}{ Race } \\
\hline White & 151 & 79.4 \\
\hline Non-white & 39 & 20.5 \\
\hline \multicolumn{3}{|l|}{ Additional degrees held } \\
\hline Yes & 36 & 18.9 \\
\hline No & 154 & 81.0 \\
\hline \multicolumn{3}{|l|}{ Country of birth } \\
\hline USA & 129 & 68.6 \\
\hline Other in North America, Aust, NZ & 3 & 1.6 \\
\hline Central/South America, Carribean & 12 & 6.3 \\
\hline Europe & 9 & 4.7 \\
\hline China/Taiwan & 4 & 2.1 \\
\hline India/Pakistan/Bangladesh & 13 & 6.9 \\
\hline Other Asia/Pacific rim & 6 & 3.1 \\
\hline Africa & 4 & 2.1 \\
\hline Middle East & 8 & 4.2 \\
\hline \multicolumn{3}{|l|}{ Medical training outside United States } \\
\hline All & 5 & 2.6 \\
\hline Part & 43 & 22.7 \\
\hline None & 141 & 74.6 \\
\hline
\end{tabular}

included 119 from the critical care/pulmonary stratum, 130 from the oncology/haematology stratum, and 95 from the stratum of internists without specified subspecialty.

One hundred and ninety of the 344 responding physicians in the study reported requesting consultations. This group of 190 physicians was predominantly male $(79 \%)$ and white $(79 \%)$ (table 3$)$. The primary religious affiliations were Protestant $(32 \%)$ and Catholic (29\%). Nearly 39\% of respondents had attended a bioethics conference, and one fourth had been a member of a clinical ethics committee (not shown).

Physicians were predominantly in single or multispecialty groups, and the majority were in private practices (table 4). Half of the respondents practised in densely populated communities (more than 500,000 people within a 20 -mile radius), and half had an affiliation with a medical school.

DILEMMAS LEADING TO CONSULTATION REQUESTS When asked about the most recent situation that had led to an ethics consultation (question 1), physicians most frequently reported dilemmas related to end-of-life care, patient autonomy, and conflicts between or among involved persons (table 1). Religious and cultural issues, issues of professional conduct, truth-telling and confidentiality, justice issues (primarily about access to health care) and
Table 4 Practice characteristics

\begin{tabular}{|c|c|c|}
\hline & \multicolumn{2}{|c|}{$\begin{array}{l}\text { Sampled } \\
\text { Physicians }\end{array}$} \\
\hline & $N$ & $\%$ \\
\hline \multicolumn{3}{|c|}{ Number of People within 20 Mile Radius } \\
\hline Fewer than 50000 & 10 & 5.35 \\
\hline 50 to 100000 & 28 & 14.97 \\
\hline 100 to 250000 & 33 & 17.65 \\
\hline 250 to 500000 & 23 & 12.30 \\
\hline More than 500000 & 93 & 49.73 \\
\hline \multicolumn{3}{|l|}{ Practice Type } \\
\hline Solo & 13 & 6.88 \\
\hline Single/multiple specialty group & 117 & 61.90 \\
\hline Academic/military/general & 47 & 24.87 \\
\hline Other & 12 & 6.35 \\
\hline \multicolumn{3}{|l|}{ Medical School Faculty } \\
\hline Yes & 95 & 50.00 \\
\hline No & 95 & 50.00 \\
\hline \multicolumn{3}{|l|}{ Percent Covered by Managed Care } \\
\hline Up to $30 \%$ & 94 & 56.63 \\
\hline More than $30 \%$ & 72 & 43.37 \\
\hline \multicolumn{3}{|l|}{ Hospital Public or Private } \\
\hline Public & 88 & 47.06 \\
\hline Private & 99 & 52.94 \\
\hline \multicolumn{3}{|l|}{ For or Not For Profit } \\
\hline For profit & 35 & 19.02 \\
\hline Not for profit & 149 & 80.98 \\
\hline \multicolumn{3}{|l|}{ Teaching Center with University } \\
\hline Yes & 138 & 73.02 \\
\hline No & 51 & 26.98 \\
\hline \multicolumn{3}{|l|}{ Number of Beds } \\
\hline 300 or less & 75 & 39.68 \\
\hline More than 300 & 114 & 60.32 \\
\hline
\end{tabular}

questions of beneficence where physicians requested consultations to consider what was best for a patient, were less commonly reported. Some physicians cited other dilemmas such as questions regarding abortion, genetic testing, and substance abuse. Sixty-five per cent were assigned more than one code. For example when a physician described a situation involving a conflict about how to handle a patient's request for care at the end of life this response was assigned three codes (end-of-life issues, patient autonomy and conflict).

TRIGGERS OF CONSULTATION REQUESTS

We present samples of verbatim responses to illustrate the various types of triggers. Following are examples of category 1 responses-the more conflict-laden or emotionally charged triggersreported in $57 \%$ of analysed responses.

\section{Resolving conflicts}

About one-third of responses were initiated to get help resolving a conflict. Many physicians described their frustration when conflicts led to ethics consultations: "[There was] an impasse between all of us ... we couldn't agree, it came to a standoff". According to another respondent: "It had just gotten very difficult dealing with the family, and I naively thought that bringing in another party might help". Conflicts often arose when a patient was near the end of life, and emotions were charged: "[The problem was] saying she was brain- 
dead with no hope, and having the husband say 'you're wrong'".

Interacting with a 'difficult' patient or family member Similarly, $10 \%$ of responses described a request for help when interacting with a difficult patient, family, or surrogate. One respondent observed: "The surrogate was unreasonable and not consistent with what the patient said". Another felt "there was indecision and squabbling among the family", and a third was frustrated with the "[a]ntagonism between the family and the operating surgeon".

\section{Emotional trigger}

Almost $9 \%$ of responses referred to an emotional trigger such as intimidation, fear, frustration, feeling at a loss about what to do, feeling uncomfortable about a situation, or encountering patient pain or suffering. A typical response began: "A man was in arrest on the ventilator. I went into the ICU and saw him on the machine. I thought this was cruel; we should not do this to the patient. I wanted to ignore the wife's wishes to do futile care, that was why we requested the consult". As with conflicts, emotional triggers also typically occurred around the end of life: "[It was my] overwhelming frustration with the excessive use of medical resources and the pain caused to the patient, [it was] a painful death instead of a dignified death".

Following are examples of category 2 responses - the more process-oriented, cognitively based or introspective triggers - which comprised $43 \%$ of analysed responses.

\section{Making a clinical decision or planning care}

Of these, $13.1 \%$ of physicians requested a consultation when they needed to make a clinical decision or plan patient care: "Both the ethics consultation and legal consultation were used, and then the decision was whether you could legally and ethically take this patient's kidneys and use them in an operation". Another physician felt that: "The patient's illness required [the] direction of a decision". In some responses, there was no available decision maker for the patient. "It was the fact that there was no immediate family member there-someone acting as power of attorney-and we felt we wanted someone else with that decision", and: "The patient's HIV status was unknown to the family and the patient was unable to make decisions".

\section{Legal or regulatory reasons}

Physicians had legal or regulatory reasons for requesting the consultation in $7.9 \%$ of responses "There was a new member of the ethics team and she knew a lot of the state laws and federal laws and we wanted to talk to her." Fear of liability sometimes triggered a request: "A family member ... said they would sue the hospital if life support was discontinued." Administrative or regulatory reasons were often involved: "They wanted to use non-approved drugs."
Thinking through ethical issues

In $4.2 \%$ of responses, physicians needed help working through the ethical issues involved. One physician wanted " $[\mathrm{t}] \mathrm{o}$ clarify what is appropriate and what is not appropriate with the dying. I wanted someone from outside to discuss this with the family". Another was struggling with the "...question as to whether it was ethical for a distant relative to make that decision".

\section{Fostering communication}

Less frequently cited reasons included a desire for assistance with communication $(3.7 \%)$. One respondent related that, in requesting the consultation: "My goal was to increase the family members' understanding and acceptance of the patient's condition". Another expressed his "... concern that [he] didn't understand all the dynamics between all the family members".

\section{Fairness and justice}

A few $(2.1 \%)$, were concerned about the fairness of some decision or decision making process, such as: "The patient was being prevented from getting the care needed" or, "Nursing staff were hearing things from the family - [they] didn't think the doctors were honouring what the patient wished".

\section{Anticipation of a bad situation}

Respondents called for consultations in $1.1 \%$ of responses because they expected a bad situation. One had: "[a] feeling that it was going to be long term with no curative treatment".

\section{Other responses}

Other factors were cited by physicians in $2.6 \%$ of responses. In $6.3 \%$ of responses, the physician referred back to the initial description of the ethical dilemma, without offering additional insight into the motivation for involving an ethicist. In a further $3.6 \%$ of responses, the physician indicated that someone else asked for the consultation.

\section{ASSOCIATION BETWEEN RESPONDENT}

CHARACTERISTICS AND TRIGGERS

Univariate and multivariate analyses were utilised to determine what factors may be associated with a greater likelihood of requesting an ethics consultation triggered by conflict or other distressful situation. In the univariate analyses, no factors were significant at the .05 level (table 5). Moderately significant factors $(\mathrm{p}<.15)$ including ethnicity of the physician (white $\mathrm{v}$ non-white; $\mathrm{p}=.08$ ), physicians who had all their training in the US $(p=.12)$; community size $(<500,000$ vs $>500,000 ; p=.06)$, and number of bioethics rounds attended $(<5$ vs $>5$; $\mathrm{p}=.09$ ) were included in a multivariate logistic regression model.

The results of the multivariate model (table 6) were the following: physicians of white race were less likely to have requested an ethics consultation in response to a conflict, a difficult patient or family, or some other emotionally charged issue. 
Table 5 Results of univariate logistic regressions on type of trigger response

\begin{tabular}{|c|c|c|c|c|}
\hline Term & $A$ & $B$ & $O R^{\star}$ & Prob $>P^{2}$ \\
\hline Gender & Male & Female & 1.45 & 0.306 \\
\hline Years in practice $\dagger$ & 20 or more & Less than 10 & 1 & 0.997 \\
\hline Race/ethnicity & White & Other & 0.49 & 0.08 \\
\hline Community size (within 20 miles) & $>500000$ & $\leqslant 500000$ & 0.55 & 0.056 \\
\hline Additional degrees & Yes & No & 0.88 & 0.746 \\
\hline Country of birth & USA & Other & 1.3 & 0.412 \\
\hline Training in USA & All of it & Not all of it & 1.74 & 0.119 \\
\hline Practice type & Solo/group practice & University/military/Hospital/resident & 0.98 & 0.953 \\
\hline Medical school faculty & Yes & No & 1.23 & 0.501 \\
\hline$\%$ reimbursement from managed care & $>30 \%$ & $\leqslant 30 \%$ & 1.3 & 0.428 \\
\hline Private or public hospital & Private & Public & 0.93 & 0.815 \\
\hline Profit or non-for-profit & Profit & Not-for-profit & 0.99 & 0.982 \\
\hline Teaching center affiliated & Yes & No & 0.89 & 0.723 \\
\hline Patient beds & $>300$ & $<300$ & 1.23 & 0.517 \\
\hline Bioethics rounds attended & 6 or more & 5 or less & 0.57 & 0.093 \\
\hline Attended bioethics conference & Yes & No & 0.91 & 0.77 \\
\hline Ever member of bioethics committee & Yes & No & 0.97 & 0.931 \\
\hline Ties with current members of ethics committee & Yes & No & 1 & 0.997 \\
\hline Recent situation included end-of-life issues & Yes & No & 0.92 & 0.828 \\
\hline
\end{tabular}

Moderately significant terms are in bold.

${ }^{\star}$ Odds ratios $>1$ indicate that physicians in group A were more likely to request an ethics consultation for conflict or distress reasons. †Physicians in the 10-19 year group were excluded from this analysis.

Table 6 Results of multivariate logistic regression on type of trigger response (using terms significant in the univariate analyses)

\begin{tabular}{|c|c|c|c|c|}
\hline Term & $A$ & $B$ & $O R^{\star}$ & Prob $>P^{2}$ \\
\hline Intercept & & & & 0.060 \\
\hline Race/ethnicity & White & Other & 0.32 & 0.016 \\
\hline Community size (within 20 miles) & $>500000$ & $<500000$ & 0.57 & 0.072 \\
\hline Training in USA & All of it & Not all of it & 2.30 & 0.038 \\
\hline
\end{tabular}

Significant terms are in bold.

${ }^{\star}$ Odds ratios $>1$ indicate that physicians in group A were more likely to request an ethics consultation for conflict or distress reasons.

$(\mathrm{OR}=0.32, \mathrm{p}=.016)$. Physicians whose training took place solely in the US were more likely to have requested an ethics consultation in response to a conflict, a difficult patient or family, or some other emotionally charged issue $(\mathrm{OR}=2.30, \mathrm{p}=.038)$. To a somewhat lesser degree, physicians working in a community where less than 500,000 people lived within a 20 -mile radius of their main practice were more likely to have requested an ethics consultation in response to a conflict, a difficult patient or family, or some other emotionally charged issue. $(\mathrm{OR}=0.57, \mathrm{p}=.072)$.

\section{Discussion}

This analysis indicates that the triggers that prompt ethics consultations differ in most cases from a straightforward request for a description and analysis of the ethical issues at hand. The most common factors that triggered physicians' requests for ethics consultation were 1) wanting help resolving a conflict; 2) wanting assistance interacting with a difficult family, patient, or surrogate; 3) wanting help making a decision or planning care, and 4) emotional triggers. Logistical analysis indicates that physicians who are ethnically in the minority were more likely to ask for a consultation to deal with conflicts, while physicians who were trained in the United States and those from small communities were also moderately more inclined to call for consultations in response to emotionally charged situations.
Some limitations of the study must be recognised. The nature of the data collection, which involves self report, precludes our ability to examine the relationship between self reported and actual behaviour in requesting ethics consultations. In addition, all respondents were physicians, qualified in internal medicine, and predominantly specialising in oncology and critical care. Other physicians, and other health care practitioners, were not surveyed.

In this report, we describe factors that trigger clinicians to request ethics consultation and have not judged their reasonableness. However, we note that some triggers, such as the need for legal advice, are often inappropriate because ethicists are typically not legal experts.

Over half the consultation requests were triggered by a need for help in responding to conflicts, difficult patients or families, or other emotionally charged situations. This finding suggests a shift in emphasis for ethics consultation from the way it has sometimes been conceived. La Puma and Schiedermayer suggested a decade ago that the ethics consultant requires the skills of: identifying and analysing ethical problems; using and modelling reasonable clinical judgment; communicating with and educating the clinical team, patient and family; negotiating and facilitating negotiation, and teaching and assisting in problem resolution. ${ }^{2}$ Similar descriptions of the skills required for ethics consultation have been offered by a number of writers 
including Fletcher and Siegler, ${ }^{3}$ Moreno, ${ }^{4}$ Andre, ${ }^{5}$ and the American Society of Bioethics and Humanities in their Core Competencies for Health Care Ethics Consultation. ${ }^{6}$ The data presented here confirm that, in general, these skills are indeed the ones that clinicians are requesting. However, while identifying and analysing ethical dilemmas are important skills, these findings suggest there should also be a strong emphasis on the skills of conflict or even crisis resolution, and on handling emotionally charged situations.

The data suggest further that in offering their skills, ethicists must be adept at identifying the particular needs of the clinician. The ethicist must do more than grasp the clinical situation and analyse it from an ethical standpoint. The factors that trigger a consultation request must be clearly identified so they can be properly addressed. The data also suggest that the consultant should help the clinician move beyond the precipitating concern to an analysis that helps the clinician learn from the situation and develop skills to address the same sort of situation in the future. While education has long been seen as an important element of ethics consultation, ${ }^{7}$ it appears that such teaching should ideally include proficiency in dealing with discord in clinical relationships.

Several authors have recently focused on the role of the ethicist as mediator. Walker has commended the shift toward this role as a positive philosophical shift "from thinking about morality as a theory applied to cases, to thinking about morality as a medium of progressive acknowledgment and adjustment among people in (or in search of) a common and habitable moral world". ${ }^{8}$ This view is furthered by a growing contingent of ethicists who, drawing from the theories of Habermas, see consensus building not only as an intermediate service for physicians, but also as a means to the end of building defensible moral theory. ${ }^{9}$

The frequency with which physicians report calling upon ethics consultants to mediate conflict also points to the value of having ethicists involved at an early stage in particularly difficult medical situations. Early involvement might reduce conflicts and thus be helpful to patients, their families and clinicians. ${ }^{10}$ Since conflicts are difficult to resolve once they have developed, early communication may reduce conflict. ${ }^{11}$

We note that conflicts were a more prevalent concern for minority physicians and physicians fully trained in the United States. We are cautious in asserting the validity of this finding because of the small number of minority physicians in the study. We can only speculate about possible reasons for the observation. Perhaps physicians in these groups either experience or perceive more conflicts.
Physicians who represent minorities may experience more conflict-laden encounters with patients. Their patients may differ culturally from them and they may have disagreements as a result of this. They and their patients may face greater disadvantages that lead to greater conflicts.

As health care organisations review existing services, or look to establish ethics consultation services and hire or train ethics consultants, it is desirable for them to appreciate the motivations of clinicians who will seek these services. ${ }^{12}$ As physicians are prompted to seek consultation to resolve conflicts and defuse emotionally charged situations, the ethicist will often have the intricate task of mediating a conflict-laden situation, while at the same time offering ethical analysis to shed light on the dilemmas at hand.

Gordon DuVal, SfD, is Bioethicist at the Centre for Addiction and Mental Health and University of Toronto, Foint Centre for Bioethics, Toronto, Canada. Leah Sartorius is Research Assistant in the Department of Clinical Bioethics, the National Institutes of Health, Bethesda, Maryland, USA. Brian Clarridge, PhD, is a Senior Research Fellow, Centre for Survey Research, University of Massachusetts, USA. Gary Gensler, $M A$, is a Statistician at the EMMES Corporation, Potomac, Maryland, USA. Marion Danis, MD, is Head of the Section on Ethics and Health Policy in the Department of Clinical Bioethics, Clinical Centre, National Institutes of Health, Bethesda, Maryland, USA.

\section{References}

1 Jonsen AR, Siegler M, Winslade WJ. Clinical ethics: a practical approach to ethical decisions in clinical medicine [4th ed]. New
York: McGraw-Hill Health Professions Division, 1998.

2 La Puma J, Schiedermayer DL. Ethics consultation: skills, roles, and training. Annals of Internal Medicine 1991;114:15560 .

3 Fletcher JC, Siegler M. What are the goals of ethics consultation? A consensus statement. Fournal of Clinical Ethics 1996;7:122-6.

4 Moreno JD. Ethics consultation as moral engagement. Bioethics 1991;5:44-56.

5 Andre J. Goals of ethics consultation: toward clarity, utility, and fidelity. Fournal of Clinical Ethics 1997;8:193-8.

6 American Society for Bioethics and Humanities. Core competencies for health care ethics consultation. Glenview, Illinois: American Society for Bioethics and Humanities, 1998.

7 Ross JW. Health care ethics committees: the next generation. Chicago, Illinois: American Hospital Publishing, 1993.

8 Walker MU. Keeping moral space open. New images of ethics consulting. Hastings Center Report 1993:23:33-40.

9 Casarett DJ, Daskal F, Lantos J. The authority of the clinical ethicist. Hastings Center Report 1998;28:6-11.

10 Dowdy MD, Robertson C, Bander JA. A study of proactive ethics consultation for critically and terminally ill patients with extended lengths of stay. Critical Care Medicine. 1998;26:2529.

11 Danis M. The promise of proactive ethics consultation. Critical Care Medicine. 1998;26:203-4.

12 Fox MD, McGee G, Caplan A. Paradigms for clinical ethics consultation practice. Cambridge Quarterly of Healthcare Ethics 1998;7:308-14. 